\title{
Responsive Teaching in Undergraduate Engineering Courses
}

\section{Dr. Aaron W. Johnson, University of Michigan}

Aaron W. Johnson is a postdoctoral research fellow at the University of Michigan. He received his Ph.D. in Aeronautics and Astronautics from the Massachusetts Institute of Technology in 2014, after which he served as a postdoctoral research fellow at the Tufts University Center for Engineering Education and Outreach. Aaron also obtained a master's degree from MIT in 2010 and a bachelor's degree from the University of Michigan in 2008, both in aerospace engineering.

\section{Dr. Cynthia J. Finelli, University of Michigan}

Dr. Cynthia Finelli is Associate Professor of Electrical Engineering and Computer Science, Associate Professor of Education, and Director of Engineering Education Research at University of Michigan. Her research areas include student resistance to active learning, the impact of the classroom space on teaching and learning, the use of classroom technology to increase student learning and engagement, and faculty adoption of evidence-based teaching practices. She recently led an international initiative to develop a taxonomy for the field of engineering education research. Dr. Finelli is a Fellow of the American Society of Engineering Education, Associate Editor for the IEEE Transactions on Education, and past chair of the Educational Research and Methods Division of ASEE. She founded the Center for Research on Learning and Teaching in Engineering at University of Michigan in 2003 and served as its Director for 12 years. 


\title{
Responsive Teaching in Undergraduate Engineering Courses
}

\begin{abstract}
Formative assessment is often conceptualized as an ongoing, informal process wherein instructors elicit and assess student thinking within the context of existing classwork. They can then use this feedback to make adjustments to their teaching. Some researchers, while agreeing with this definition, argue that much of the existing formative assessment research focuses on what teachers do, rather than what students think. Instead, they reframe formative assessment as responsive teaching, an instructional approach in which teachers elicit student thinking around a particular topic, notice and interpret the disciplinary substance contained within students' thinking, and then respond in real-time in order to support students' disciplinary behaviors. Responsive teaching has been studied for some time in K-12 mathematics and science education, and it has recently become a focus in K-12 engineering education. However, to our knowledge no research has investigated responsive teaching in undergraduate engineering education. We intend to begin a conversation about this important area of study through three specific aims of this paper: 1) introduce new engineering educators to prior research on responsive teaching, 2) discuss how formative assessment was used in two undergraduate engineering science courses and investigate whether these practices afford responsive teaching, and 3) suggest ways new engineering educators can incorporate responsive teaching practices into their own teaching.
\end{abstract}

\section{Introduction}

New engineering educators often employ formative assessment in their classes without considering it too deeply. In contrast to summative assessments - such as quizzes, exams or project reports - that occur infrequently and at the end of a particular unit or activity, formative assessment is ongoing and integrated into the lesson. Formative assessment gives instructors feedback about student learning, which they can use to make adjustments to their teaching.

One definition of formative assessment is offered by Black and Wiliam (2009):

Practice in a classroom is formative to the extent that evidence about student achievement is elicited, interpreted, and used by teachers, learners, or their peers, to make decisions about the next steps in instruction that are likely to be better, or better founded, than the decisions they would have taken in the absence of the evidence that was elicited. (p. 7)

However, there are multiple viewpoints on the methods by which this evidence should be elicited. One view interprets formative assessment as a formal diagnostic test that produces a score quantifying student achievement, while another sees formative assessment as an informal process wherein instructors elicit and assess student thinking within the context of existing classwork (Popham, 2008; Bennett, 2011). This second viewpoint places emphasis on the instructor's response- how he or she uses this understanding of student thinking to modify the lesson in real-time (Black \& Wiliam, 1998; Bennett, 2011).

While Coffey, Hammer, Levin, \& Grant (2011) agree that formative assessment should be informal and ongoing, they claim that much of the existing formative assessment research 
focuses on what teachers do, rather than what students think. Critiquing examples of "good" formative assessment from four prominent papers in the field, they argue that the teachers in these examples do not truly attempt to understand their students' ideas. Rather, the teachers elicit and respond to student thinking in pursuit of "content" as "a body of correct information, centered on terminology, and selected in advance as lesson objectives" (Coffey, Hammer, Levin, \& Grant, 2011, p. 1114).

The authors reframe formative assessment as responsive teaching, an instructional approach in which teachers elicit student thinking around a particular topic, notice and interpret the disciplinary substance contained within students' thinking, and then respond in real-time in order to support students' disciplinary behaviors (Hammer, Goldberg, \& Fargason, 2012; Robertson, Scherr, \& Hammer, 2015). As Hammer, Goldberg, \& Fargason (2012) describe responsive teaching in science classrooms:

A responsive approach [to teaching] [...] is to adapt and discover instructional objectives responsively to student thinking. The first part of a lesson elicits students' generative engagement around some provocative task or situation (or, perhaps, by discovering its spontaneous emergence). From there, the teacher's role is to support that engagement and attend to it — watch and listen to the students' thinking, form a sense of what they are doing, and in this way identify productive beginnings of scientific thinking. (p. 55)

The parallels between this definition of responsive teaching and Black \& Wiliam's (2009) definition of formative assessment are clear. Both involve eliciting and using student feedback to shape the future direction of a lesson or class. However, the difference is in responsive teaching's focus on noticing and responding to the disciplinary substance of students' ideas. This is the important missing piece that Coffey, Hammer, Levin, \& Grant (2011) argue is absent in traditional conceptualizations of formative assessment.

Responsive teaching has been studied for some time in K-12 mathematics and science education, and it has recently become a focus in K-12 engineering education. However, to our knowledge no research has investigated responsive teaching in undergraduate engineering education. We intend to begin a conversation about this important area of study through three specific aims:

1. Introduce new engineering educators to prior research on responsive teaching

2. Discuss how formative assessment was used in two undergraduate engineering science courses and investigate whether these practices afford responsive teaching

3. Suggest ways new engineering educators can incorporate responsive teaching practices into their own teaching

\section{Responsive Teaching Background}

Mathematics and science education researchers have investigated multiple dimensions of responsive teaching. One thread of research has focused on the benefits of responsive teaching to students. Empirical studies have shown that responsive teaching enhances conceptual understanding in students (Empson \& Jacobs, 2008; Pierson, 2008) and supports students' 
engagement in disciplinary practices (Ball, 1993; Coffey, Hammer, Levin, \& Grant, 2011; Richards, 2013).

Other research has focused on how teachers engage in responsive teaching. In mathematics education, Sherin and collaborators investigated the effectiveness of "videos clubs" in helping teachers to develop their ability for responsive teaching (Sherin \& Han, 2004; Sherin \& Van Es, 2009). In these studies, groups of mathematics teachers and researchers watched and discussed video captured during the teachers' lessons. Through these video clubs, teachers developed their ability to notice and interpret student thinking while watching video in the club (Sherin \& Han, 2004) and in their teaching outside of the club (Sherin \& Van Es, 2009). Another thread of research in science education has suggested that an instructor's beliefs and perspectives can influence the way he or she notices and responds to certain aspects of student behavior and thinking (Levin, Hammer, \& Coffey, 2009; Lau, 2010; Maskiewicz \& Winters, 2010). Lastly, a group of mathematics and science education studies have described how the authors, who were at one point teachers themselves, navigated "instructional tensions" when employing responsive teaching during class (Ball, 1993; Hammer, 1997; Chazan \& Ball, 1999). These authors reflected on the challenges of trying to simultaneously value student participation, students' ideas about mathematics and scientific phenomena (even if these ideas were incorrect), and the conventional mathematical or scientific understanding that students were expected to learn.

These findings about responsive teaching in mathematics and science education help to inform responsive teaching in engineering education. However, it is also important to consider responsive teaching in engineering as distinct from responsive teaching in these other disciplines, because responsive teaching, by its very nature, focuses on disciplinary substance (Coffey, Hammer, Levin, \& Grant, 2011). And, the disciplinary substance of engineering is distinct from that of mathematics and science. Despite the importance of studying responsive teaching in engineering directly, this has only become a recent focus in the community. Wendell, Watkins, \& Johnson (2016) used prior literature on disciplinary targets of instruction to develop a framework for three areas of focus during responsive teaching in engineering: "1) students' conceptual ideas; 2) students' engagement in design practices, processes and discourse; and 3) students' perspectives within and about engineering" (p. 2). The first two components of this framework — students' ideas and practices_-address the disciplinary substance of engineering design, while the third component — students' perspectives - addresses ways that students participate in engineering design. After developing this framework in their paper, Wendell, Watkins, \& Johnson (2016) discussed "instructional tensions" that they themselves faced in responding to elementary students' engineering designs.

Other research has focused on teachers' ability to notice and respond to student thinking in engineering. Mangiante \& Moore (2016) investigated what pre-service teachers (i.e. undergraduate students studying education) new to engineering attended, analyzed, and responded to when working with fourth grade students during engineering activities. The authors analyzed written reflections from the pre-service teachers and assessed their attention to three disciplinary practices - defining the engineering problem, designing solutions, and optimizing solutions (NGSS Lead States, 2013) — as having a low, medium, or high focus on student thinking. The authors found that the pre-service teachers had more sophisticated reflections about attending to student thinking than about analyzing or responding to student thinking. 
McCormick, Wendell, \& O'Connell (2014) showed video of students engaged in engineering design to five in-service teachers (i.e. practicing elementary school teachers) new to engineering and then interviewed the teachers about what they noticed and how they might respond to the students. The researchers categorized four themes of teacher noticing and three themes of hypothesized responses. The results suggested that while these teachers were new to engineering, they still exhibited productive beginnings of responsive teaching in engineering. In another study as a part of the same project, Johnson, Wendell, \& Watkins (2016) categorized what in-service teachers who were experienced in engineering noticed when they watched and reflected on videos of their own students engaged in engineering design. The authors found that these "experienced teachers" were capable of noticing disciplinary substance in their students' thinking, such as how students engaged in the engineering design process and how students interpreted the project (their perspective (Wendell, Watkins, \& Johnson, 2016)). Even so, these experienced teachers reflected on challenges in responding to their students' engineering design, such as questioning how much to guide their students toward productive engineering behaviors.

All of this prior research on responsive teaching in engineering has occurred in K-12 education - specifically at the elementary level. To our knowledge, no research has focused on responsive teaching in undergraduate engineering education. While the findings and recommendations of the K-12 literature can begin to help new engineering educators to engage in responsive teaching, the context is very different. Class size is one example. During the 20142015 academic year, the median number of students in a first grade classroom in Michigan was twenty-five (Jacob, Crespin, Libassi, \& Dynarski, 2016). Undergraduate engineering classes can have many times this number of students. The two undergraduate courses in this study, for example, had forty and eighty-one enrolled students, and in fall 2016, the introductory programming course 7at the university studied in this paper had three sections each with an enrollment between 235-248 students. While elementary teachers can walk around and interact with every student group during an engineering design challenge, this is impossible for many large undergraduate engineering classes.

Another difference is that the focus in K-12 engineering education is solely on design. The Next Generation Science Standards (NGSS), developed in 2013 and adopted (exactly or slightly modified) in 21 states and the District of Columbia, address three Disciplinary Core Ideas of engineering across grades: 1) defining and delimiting an engineering problem, 2) developing possible solutions, and 3) optimizing the design solution (NGSS Lead States, 2013). Teachers satisfy these standards by developing engineering design projects for their students - for example, having students design, build, and test an assistive device to help a dog with paralyzed hind legs get around. While teachers may choose to connect engineering design projects with their science lessons, this does not always occur and is not necessary to meet the NGSS.

On the other hand, while undergraduate engineering education certainly includes design, a large portion of the curriculum is comprised of math-intensive engineering science classes. As a result, the disciplinary substance of students' engineering is different-specifically with regards to students' practices (Wendell, Watkins, \& Johnson, 2016). Instead of the engineering design process (Dym, Agogino, Eris, Frey, \& Leifer, 2005), practices in undergraduate engineering science courses include behaviors like employing problem-solving strategies that address a 
particular class of closed-ended problems, and developing mathematical models of open-ended problems that allow them to be solved.

And third, undergraduate instructors are already experts in the engineering content they teach, whereas elementary teachers often have no training in teaching engineering. So, while new engineering educators must learn how to enact responsive teaching, elementary teachers must learn these practices in addition to the engineering content. While this gives new engineering educators an advantage, research has shown that being a content expert does not completely remove tensions when engaging in responsive teaching (Ball, 1993; Hammer, 1997; Chazan \& Ball, 1999; Wendell, Watkins, \& Johnson, 2016; Johnson, Wendell, \& Watkins, 2016).

Thus, there is a need for more research that specifically investigates responsive teaching in undergraduate engineering education. This paper initiates this conversation. In the following sections, we investigate the ways in which formative assessment practices in two undergraduate engineering science courses afford responsive teaching. Then, we suggest ways new engineering educators can incorporate responsive teaching practices into their own teaching. Rather than providing research-based strategies, this paper aims to help new engineering educators become more reflective about their own teaching practices (particularly regarding methods of formative assessment) and to encourage new educators to think about how they currently use formative assessment in their own classes, how they can create more opportunities to elicit and notice student thinking, and how they can become more responsive to student thinking during class.

\section{Study Context}

The two courses studied in this paper, Aerodynamics and Dynamics \& Vibrations, were held during the fall 2016 semester at a large, public, research-intensive university in the Midwest. Aerodynamics is a required course for students in the aerospace engineering department, most of whom take the course during their junior year. The course covers topics such as kinematics, dynamics, potential flow, thin airfoil theory, viscous flow, and turbulent flow. Only one section was offered during fall 2016, and forty students were enrolled. The instructor, referred to as Professor Aero, was a male assistant professor in the aerospace engineering department. He had taught the Aerodynamics course once before, three years ago. The Aerodynamics course was held in a newly renovated "flexible" classroom with a flat floor and movable tables and chairs. However, Professor Aero did not take advantage of this flexibility, and for each class period, the room was arranged in rows of tables facing front. Aerodynamics was selected for observation because it was a lecture-based engineering science course (as opposed to a discussion course or a design-based course) held in the new flexible classroom. Professor Aero heavily used the whiteboard at the front of the classroom, and also occasionally used his computer and the projector to show PDFs, visualizations, and movies.

Dynamics \& Vibrations is a required course for students in three different engineering departments, and most students take the course during their sophomore year. It covers how Newton's Laws, work and energy, and impulse and momentum are used to solve kinetics and kinematics problems. Mechanical vibrations are also covered at the end of the semester. We 
observed one of the three sections of Dynamics \& Vibrations offered during fall $2016 .{ }^{1}$ The instructor, referred to here as Professor DV, was a male tenured professor in the Mechanical Engineering department who had been teaching dynamics and vibrations for thirty years. Eightyone students were enrolled in this section of Dynamics \& Vibrations, and it was held in a traditional "lecture-style" amphitheater classroom with tiered rows of fixed tables. Dynamics \& Vibrations was selected for observation because Professor DV was known to heavily employ active learning activities in class, and because the class was held in a traditional classroom. Professor DV used the whiteboard at the front of the classroom every day, and occasionally did pre-planned or spontaneous demonstrations for students.

\section{Methods}

During the fall 2016 semester, we collected data from the Aerodynamics and Dynamics \& Vibration courses in the form of 1) pre- and post-semester interviews with each instructor, 2) coding of pedagogy during classroom observations, and 3) field notes made during classroom observations. The pre-semester interviews were conducted before (Aerodynamics) or on (Dynamics \& Vibrations) the first day of class, were semi-structured, and used a standardized interview protocol. Each interview addressed the instructor's class goals, methods of receiving feedback on students' learning, teaching strategies, use of technology, teaching professional development, and preferred classroom features.

Each class comprised forty meetings during the semester. We observed the first eleven meetings of Dynamics \& Vibrations and the first ten meetings of Aerodynamics. Per Professor Aero's request, we did not observe the first meeting of Aerodynamics. We then returned to observe the last seven meetings of both classes. During these observations, we used the Teaching Dimensions Observation Protocol to capture the instructor pedagogy and student activities in two-minute increments (Hora, 2015). We augmented these codes with extensive field notes and reflections made immediately after class meetings.

We conducted the post-semester interviews soon after the last day of class. To prepare for these interviews, we reviewed the pre-semester interviews, observations, and field notes, and developed an instructor-specific interview protocol that included standardized, general questions and questions about specific pedagogical moves we observed during the semester. These instructor-specific protocols were then used for semi-structured interviews with each instructor.

After data collection was completed, we reviewed the full data set for each course to identify 1) the formative assessment strategies used by each instructor and 2) the instructor's intent for using these strategies. Then, we used this information to assess whether these formative assessment strategies afford instructors the opportunity to notice or respond to the disciplinary substance of student's thinking. Unlike prior research on responsive teaching (Coffey, Hammer, Levin, \& Grant, 2011; McCormick, Wendell, \& O’Connell, 2014; Mangiante \& Moore, 2016; Johnson, Wendell, \& Watkins, 2016), we do not analyze transcripts of student-teacher interactions, so we cannot make definitive claims about whether or not the instructors in our study did or did not elicit and respond to disciplinary substance. This is left for future work. Instead, here we discuss

\footnotetext{
${ }^{1}$ As this paper does not address the other two sections of Dynamics \& Vibrations, the term "Dynamics \& Vibrations" is used henceforth to specifically refer to Professor DV's section of the course.
} 
how the formative assessment strategies used by the two instructors have the potential to provide opportunities for responsive teaching.

\section{Responsive Teaching in the Aerodynamics Course}

The primary pedagogy employed in Aerodynamics was lecture-Professor Aero spent much time at the board working through mathematical derivations and examples. This is not to say, however, that students were disengaged. Professor Aero employed a number of pedagogical techniques in order to engage students: he asked questions during his lecture, he encouraged students to ask questions, and he paused to check students' conceptual understanding. Professor Aero also posed multiple-choice questions that each student could respond to using a personal student response system (a "clicker"). In the pre-semester interview, Professor Aero commented that he was inspired to use these "clicker questions" by another colleague who also taught Aerodynamics. Of the seventeen Aerodynamics class meetings observed, clicker questions were asked in five classes, four of which were during the first month of class. This included one class where Professor Aero was traveling and the graduate teaching assistants taught the class.

In the post-semester interview, Professor Aero discussed his two objectives for posing clicker questions in class. He stated, "Basically, first [it's] for me to get feedback on whether [the students] understand the material. And two, of course, it's a learning tool.", To obtain this feedback, Professor Aero asked students to answer the clicker questions on their own, without help from their classmates. As he explained in the post-semester interview:

When I ask a question in class it's the same ten kids that always answer. So, I get a sense of what [the other students] understand and what they don't [through the clicker questions]. And, [...] I also monitor how different parts of the course are being received. And more or less they do [the clicker questions] without any help from the other students, whereas I think $[\ldots]$ they collaborate quite a bit [on homework].

Classroom observations confirmed that having students work on clicker questions by themselves was important to Professor Aero; on a number of occasions he reminded students to work independently when he heard talking after he posed a question. We did not observe any times in which Professor Aero used the clicker question as a group learning activity in the style of Peer Instruction, in which he would have asked students to discuss their chosen answer with each other before he gave the correct answer (Mazur, 1997). This also supports Professor Aero's comment that individual assessment was the primary goal of clicker questions.

The way in which Professor Aero responded to a given clicker question depended upon the results. In general, if most of the class selected the correct answer, he confirmed this and continued on with a brief explanation. However, when the class was split on an answer, he usually spent more time on an explanation. In some cases he presented the correct answer first and then explained how it was found, and in other cases he worked through the problem to arrive at the correct answer. Lastly, when students continued to have questions about why their chosen answer was incorrect, Professor Aero spent additional time reviewing the correct answer and

\footnotetext{
${ }^{2}$ Instructor quotations have been cleaned to remove filler words, restarted phrases, repeated words or phrases, and to generally make the quotation easier to read and understand. The substance of the quotation has not been changed.
} 
discussing the methodology with students. During the discussion of one particularly confusing question, we observed a number of students actively participating and describing their reasoning behind choosing the incorrect answer. By volunteering their thinking about the problem, Professor Aero had the opportunity to notice and respond to the disciplinary substance of the students' thinking. However, beyond these discussions of particularly-challenging questions, the way in which Professor Aero used clicker questions did not easily afford responsive teaching.

Beyond responding to the clicker questions immediately after they were answered, Professor Aero also used the feedback from the clicker questions to shape the agenda for his course on a longer time scale. In the post-semester interview, he stated:

I also throw in some incredibly basic questions, which I expect $100 \%$ of them to get. If not, then I slow down a little bit for the next lectures. And also, another interesting thing with [the clickers] is that in many of the questions an option is "I do not understand the question." So that is a red flag for me. And in some questions I got like, $30 \%$ or $20 \%$ [of students] that didn't understand the question. And that was an issue. So I maybe slow down the next few lectures or I make it a point to emphasize that material downstream.

\section{Challenges of Responsive Teaching}

Limitations of Clicker Questions: While the clicker questions provided formative feedback, they provided it at the class level in the form of the percentage of students that selected each answer. Professor Aero could have looked deeper at the results to see which students were getting the question correct or incorrect, but he did not do this. (In the post-interview he stated that this is something he would like to incorporate the next time he teaches the course.) As a result, he did not know if there were students who were consistently getting the questions incorrect. More importantly, the student response system used across the university - and therefore in Aerodynamics - required Professor Aero to ask multiple-choice questions. Limiting students' possible responses made it difficult to assess the disciplinary substance of their thinking, as students were not free to express what they were thinking in an open-ended manner. One way to temper this limitation would be for instructors to design multiple-choice answers that result from common mistakes or misconceptions that students might make, as is commonly done with concept inventories (e.g. the Dynamics Concept Inventory (Gray, Evans, Cornwell, Costanzo, \& Self, 2005), the Strength of Materials Concept Inventory (Richardson, Steif, Morgan, \& Dantzler, 2003), and the Thermodynamic Concept Inventory (Midkiff, Litzinger, \& Evans, 2001)). However, this still would not allow instructors to elicit and respond to unexpected avenues of student thinking that may result.

Lack of Student Participation: While the clicker questions provided Professor Aero with valuable feedback, they did not easily afford responsive teaching. As has been stated, this was due to both the limitations of the student response system and the way in which Professor Aero used clicker questions in class. As a result, student questions represented the primary opportunity for Professor Aero to elicit disciplinary substance of student thinking. Professor Aero encouraged students to ask questions on numerous occasions. However, when asked in the post-semester interview if he was happy with the level of participation, Professor Aero said he was "reasonably" happy, but then noted that class had the least participation of any he had taught in 
his three years at the university. He then continued on to reflect on the fact that this wasn't because of a lack of questions:

Many times - almost every single lecture - after I finish students come to me and ask me questions. And I ask them, "Why didn't you ask it in class?" [They say,] "I don't wanna feel stupid." The peer pressure, I think, is a lot more here. And I get a lot more questions in the office hours. Specifically on, "in the lecture you mentioned this and I didn't understand." And, I would have had this one hundred, two hundred times in office hours. [I ask,] "Why didn't you ask me the question?" [And they say,] "The class is full of geniuses." You know, "I didn’t want to feel stupid." Or, "My question is too basic."

This quotation emphasizes the fact that successful responsive teaching in large undergraduate engineering classes involves actions by both the instructor and students. As much as the instructor may work to elicit student thinking, responsive teaching still requires action from the students. It is impossible to notice student thinking when the students do not volunteer it.

\section{Responsive Teaching in the Dynamics \& Vibrations Course}

Professor DV had learned about active learning pedagogy a few years prior, and he incorporated these activities extensively into his class. During the pre-semester interview, he spoke enthusiastically about the use of active learning as a way to have students think on their own and "attempt to take a concept and bring it to bear on [an] example." He then continued on, stating that an additional goal of active learning was to have students "challenge each other as to whether or not they're doing that well [and correctly]. And debating among themselves the [...] several ways of applying that concept to that example."

Our observations and field notes confirmed that active learning activities were an integral part of Dynamics \& Vibrations. Professor DV lectured to students when introducing a new concept or topic, but the majority of class time was spent working through example problems following a particular intentional process. This "flow," as Professor DV named it, combined group problem solving with instructor feedback and lecture. Based on observations, field notes, and interviews, this flow for a given example problem can be generally outlined as follows:

1. Introduction: Professor DV introduced a new example by drawing a mechanical system on the board and describing the goal of the problem. He then asked students to work with their neighbor to get started solving the problem. In particular, he emphasized the importance of the problem-solving process over finding the right answer. This theme of process over answer was pervasive throughout the class from the first meeting, and was also discussed in Professor DV's pre-semester interview.

2. Group Problem Solving: As students were working on the problem, Professor DV walked around the classroom. This served two purposes:

a. It allowed Professor DV to check on students' progress to know when to bring the class back together to discuss the problem.

b. It gave students an opportunity to raise their hands and ask private questions one-on-one with Professor DV. 
3. Checking Progress: Professor DV asked students to raise their hands if they had finished particular steps of the problem, such as drawing a free-body diagram or choosing a coordinate system (e.g. Cartesian or polar).

4. Identifying a Sticking Point: Professor DV asked students to suggest one thing that he could help them to understand that would assist them in solving the problem. Through this question, he invited a student to volunteer a sticking point, thereby implicitly eliciting a student's problem solving strategy.

5. Eliciting a Student's Strategy: Sometimes, in addition to or instead of step 4, Professor DV explicitly asked for a volunteer to share how he or she began solving the example problem. Through this invitation, he explicitly elicited a student's problem-solving strategy.

6. Solving the First Step: Whether he elicited a sticking point (step 4) or an explicit problemsolving strategy (step 5), Professor DV used students' responses as the starting point for solving the first step of problem on the board in front of the class.

7. Asking Questions: As he was solving the problem on the board, Professor DV frequently asked questions of the students. In many of these questions he was looking for one particular correct answer. Students responded to these questions in a variety of ways. For example, an individual student would respond, students would call out an answer as a group, students would raise hands to vote for the answer of a multiple choice question, or students would point with their fingers (e.g. in the direction of a particular vector).

8. More Group Problem Solving: After setting up the first step, Professor DV asked students to work ahead of him and find the answer for the first step of the problem. Professor DV continued to work out the first step on the board.

9. Confirming the Intermediate Answer: When Professor DV finished the first step, he asked students to raise their hands if they got the same answer that he did. A number of times students disagreed and corrected minor mistakes that Professor DV had made.

10. Inviting Questions: After solving the first step, Professor DV stopped and invited questions by stating, "Ask me a question." This phrase was constantly used throughout the semester, and, as is discussed later in the paper, was deliberately chosen.

11. Checking Conceptual Understanding: When there were no further student questions, Professor DV asked students to raise their hands if they understood $90 \%$ of the previous discussion. If he saw a lot of hands raised, Professor DV moved on to the next step of the problem.

12. Repeating: This flow was then repeated for each subsequent step of the problem until the final answer had been reached.

While Professor DV did not follow this exact process for every example problem, we constantly noticed these pedagogical techniques being employed throughout the semester.

Many of the steps in this process involved formative assessment: walking around during Group Problem Solving (step 2), Checking Progress (step 3), Identifying a Sticking Point (step 4), Eliciting a Student's Strategy (step 5), Asking Questions (step 7), Confirming the Intermediate Answer (step 9), Inviting Questions (step 10), and Checking Conceptual Understanding (step 11). However, these formative assessment techniques can be further categorized by their purpose. Steps 2, 3, 9 and 11 assisted with time management, informing Professor DV as to whether he could continue with the problem solving process, or if he needed to give students 
more time to work or spend more time explaining the material. Additionally, while Professor DV sometimes elicited individual student answers in step 7, these questions were often designed with a particular correct response in mind. This suggests that these questions were implemented as a form of active learning designed to engage students in the lesson, rather than elicit the disciplinary substance of student thinking.

There were then four opportunities for Professor DV to elicit the disciplinary substance of student thinking: when individual students asked private questions during Group Problem Solving (step 2b), Identifying a Sticking Point (step 4), Eliciting a Student's Strategy (step 5), and Inviting Questions (step 10). Our field notes indicate that Professor DV was capable of eliciting and responding to the disciplinary substance of students' thinking at these times. In one example, Professor DV asked students about the next step they would take to solve a problem on which the class was working. A student responded by giving a surprising answer that Professor DV did not expect (a fact that he announced to the class). This student's answer displayed disciplinary substance in the form of his problem-solving practice (Wendell, Watkins, \& Johnson, 2016). Professor DV noticed this disciplinary substance and responded by abandoning his pre-planned agenda and continuing to solve the problem as the student had suggested. As he did so, Professor DV asked the student additional questions to further elicit his problem-solving practice.

While Professor DV worked to elicit student thinking during these four steps, it is critical to note that he was only able to notice student thinking from those who volunteered it, the same as in Aerodynamics. As Professor DV stated in the post-semester interview:

It really requires students to divulge if they're understanding or not understanding. And fundamentally that means you gotta lower the barrier of the anxiety for raising your hand and asking a question. So it starts with trying to set a culture in the classroom where it's ok to ask a question [and] it's ok to speak up.

The data show that Professor DV employed multiple strategies intentionally designed to create a classroom culture in which students felt comfortable asking questions. Like Professor Aero, Professor DV continually encouraged students to ask question. However, in doing, he used the specific and intentional phrase "Ask me a question." In the pre-semester interview, Professor DV commented on his use of this specific phrase:

No doubt, when I first started [using active learning], I would ask questions using the following tone or phrases. "Do you all understand that?" "Was that clear?" [...] "Do you have any questions?" And occasionally I'll ask the same questions now. But, here's what [...] I'll do. Instead of "Do you have any questions?" now it becomes "Ask me a question." Big pregnant pause. They're starting to feel a little uncomfortable because [I'm] not saying anything. And then I get a question, and usually the question is quite representative of what the students are not understanding.

Professor DV began creating a classroom culture where questions were encouraged within the first fifteen minutes of the first class. After going through the syllabus, Professor DV invited questions about the syllabus and continually encouraged students to ask more. As he described in 
the post-semester interview, "That's done very intentionally. And slightly to the point of annoyance. I do it so that they know what's coming in the next sessions." As he called on students who raised their hands, Professor DV thanked students for their questions. This practice, which Professor DV described as explicit and intentional in the post-semester interview, continued throughout the semester. After answering questions about the syllabus for approximately seven minutes, Professor DV concluded with a statement that made his classroom culture explicit. He announced, "I want you to ask a ton of questions. Your questions are far more important than my lecture plan."

\section{Challenges of Responsive Teaching}

Even given Professor DV's thirty years of teaching experience (for which he has been recognized with the university's highest teaching award), his commitment to active learning, and intentional teacher moves to create a classroom culture in which questions were encouraged, he still found there to be challenges and tensions in enacting responsive teaching.

Classroom Layout: In the pre-semester interview Professor DV commented on how the layout of the classroom influenced his ability to answer questions during Group Problem Solving (step 2):

I want a room where I can walk between students very easily. Because I find that during those times when they are working and solving problems on their own, I get a lot of questions from them. And it happens most naturally as I walk by someone. Now they don't have to put their hand up and expose [themselves] - they just [whisper,] "Pssst, hey, can you help me here?" And I turn off my microphone [and] we go and have this little private conversation. [...] Only the students who are sitting either in the front or adjacent to [the aisles in the present classroom] are gonna have that kind of opportunity.

In the last sentence of this quotation Professor DV was commenting on his classroom for the fall 2016 semester, in which the tables were so close together than he could not move between students to answer one-on-one questions from everyone. He went on to contrast this classroom with a different classroom in which he had previously taught Dynamics \& Vibrations. While this other classroom was also a lecture-style amphitheater, there was enough space for Professor DV to move behind students and reach everyone as he walked around.

Tension Between Eliciting More Thinking or Moving On: In the post-semester interview Professor DV commented on a second challenge of enacting responsive teaching - a tension between eliciting the thinking of a few students who weren't understanding a concept and continuing on with the class:

I also worry that if there's one student that's not raising their hand, obviously I'm not going to single them out. [...] So, I have to make a judgment call-do I go back and guess at what the issue is and devote more time? Or do I move on? And, it's a little cruel sometimes, because I'll see, you know, five students that are [sitting with their hands down] and I just move on because I've got [...] 85-95\% of my students that say, "No, I'm good." So, [...] I worry about that. 
As this quote indicates, Professor DV was balancing multiple different desires: 1) to elicit the thinking of students who did not understand a concept, 2) in a way that did not single them out in front of their classmates, 3) without slowing the class down for the majority of students. As was discussed earlier in this paper, "instructional tensions" such as these occur in responsive teaching across disciplines (Ball, 1993; Hammer, 1997; Chazan \& Ball, 1999; Wendell, Watkins, \& Johnson, 2016).

\section{Discussion and Suggestions for New Engineering Educators}

As we have shown, formative assessment can have multiple uses in undergraduate engineering courses. Professor Aero used clicker questions to assess how well students understood the material by themselves and to provide feedback on the pacing of the class. He responded to the results by explaining questions missed by multiple students and by adjusting the pacing and content of subsequent lectures. Professor DV used a number of assessment techniques for time management, indicating when he could continue on with the example problem and when he should re-explain a particular step. He also used questions to keep students engaged and provide a high-level assessment of the class's understanding. While these are all valuable uses of formative assessment, they do not afford opportunities for responsive teaching. In the two classes we observed, inviting students to ask questions was the formative assessment that most afforded the instructors an opportunity to notice and respond to the disciplinary substance of students' thinking. However, this required students to ask a question and volunteer their thinking. Furthermore, both instructors still encountered challenges in noticing and responding to students' thinking through student-asked questions.

There are other methods of formative assessment not used by Professors Aero or DV that may afford opportunities for responsive teaching and should be investigated in future research. Two examples include minute papers, in which students briefly write down the most important thing they learned during class, and "muddiest point" papers, in which students write down the muddiest (i.e. "most unclear") point from class (Vanderbilt University Center for Teaching, n.d.). The instructor then collects these assessments, reads them after class, and responds to the feedback during the next class. These assessment techniques are certainly more open-ended than multiple-choice clicker questions. But, they still rely on students making their thinking visible. As a hypothetical example, a student could state that the muddiest point of a class was "understanding the direction of the friction force." Though valuable, this feedback for the instructor does not illuminate the student's engineering ideas, practices, or perspectives (Wendell, Watkins, \& Johnson, 2016).

So what can new engineering educators do to provide opportunities for responsive teaching in their large undergraduate engineering courses? Based on this study of these two engineering faculty and the advice in the literature, we offer six suggestions to give new engineering educators a starting point for reflecting on their own courses and working to incorporate responsive teaching more in their own teaching practices.

First, new engineering educators simply need to be aware of the common tensions that exist in trying to enact responsive teaching. For example, multiple different researchers discuss a tension involving encouraging students to share and pursue mathematical or scientific ideas that are 
incorrect (Ball, 1993; Hammer, 1997; Wendell, Watkins, \& Johnson, 2016). Another tension seen in the Dynamics \& Vibrations data centers around Professor DV deciding whether to continue on with his lesson or attempt to understand why some students didn't comprehend a particular concept. Being aware that tensions like these exist when instructors-even ones as experienced as Professor DV - try to enact responsive teaching will help new engineering educators to not be discouraged when they face these tensions themselves.

Second, new engineering educators should take explicit steps to create a classroom culture where questions are encouraged. New engineering educators can emulate some of the intentional teacher moves that Professor DV used to encourage questions, such as stating, "Ask me a question" or thanking students when they ask a question. However, creating this type of classroom culture requires the instructor fully commit to it. Professor DV recalled an anecdote from the first day of a class a few years ago in which he had answered many questions about the syllabus but still said, "I need one more question; I'm not gonna talk until I get a question." In response, a student asked, "What is the stupidest thing you've ever done?" In the interview, Professor DV commented that he would not have answered that off-topic question as a new instructor. But, in order to fully commit to answering all questions, he told the class the story of the stupidest thing he had ever done. And, as he recalled, this had the desired effect. He said, "I know that class realized that you can ask a question and it'll be answered."

Another important aspect of creating a classroom culture that encourages questions involves matching the instructor's explicit and implicit signals to the students. No matter how much an instructor encourages questions, students may still be hesitant to ask a question if the instructor implicitly discourages questions through his or her body language (e.g. rolling his or her eyes when the student asks a "dumb question") or the phrase used to invite questions (e.g. "Are there any quick questions? I know this is pretty easy."). Commenting on instructors who use phrases such as this, Professor DV remarked:

[Those instructors are] saying code for: "I have an agenda for today. I just covered some stuff that you should all know. If you got a quick question I can accept it in my agenda. But if it's a long question, bug off. Because I need to get to this stuff."

Third, new engineering educators should work to understand the disciplinary substance in students' thinking when students ask a question or volunteer an answer. This is a skill that requires practice, even for instructors who are content matter experts and have personal knowledge of the ideas, practices, and perspectives that make up the disciplinary substance of engineering. One way for new engineering educators to develop this skill is to organize video clubs with fellow instructors (Sherin \& Han, 2004; Sherin \& Van Es, 2009). Videotaping class meetings and watching them later gives instructors a chance to focus on noticing the disciplinary substance in students' thinking without having to worry about things such as the time left in class or answering unanticipated questions. Instructors can also watch clips repeatedly, giving them time to dig into the disciplinary substance of what students are saying and doing. In addition to giving instructors practice in noticing student thinking, video clubs also give instructors an opportunity to critique the way that they responded to students in class. They can also think about how they might have responded differently to encourage disciplinary ideas, practices, and 
perspectives. Lastly, discussing video as a group in a video club allows for multiple perspectives on what students may have been thinking and how the instructor could have best responded.

Fourth, new engineering educators should engage in responsive teaching outside of class. As the data from Aerodynamics and Dynamics \& Vibrations suggests, it is difficult to elicit, notice, and respond to individual students' thinking in large undergraduate engineering classes. However, office hours provide an opportunity for instructors to interact with students one-on-one. In these more personal settings, instructors can take more time to have discussions with students that illuminate their engineering ideas, practices, and perspectives.

Our fifth and sixth suggestions come directly from Professor DV. In the post-semester interview, we asked him, "Is there any advice that you would give to a new faculty member who wants to be responsive to student thinking or use more active learning activities in their class and has that subject matter experience but doesn't have the teaching experience?" Professor DV's first suggestion was for new engineering educators to build margin into each class in order to have time to respond to students' thinking:

I guess it comes down to [deciding] are you willing to relinquish your agenda? And instead, turn it over to the agenda of the students. I don't mean entirely. I don't mean [that] students come in, you have nothing planned, and you say, "What are we gonna talk about today, guys?" What I do mean [is] for new instructors [to] plan an agenda that you need to get to, kinda bottom-line, this is what I want to achieve today. But make sure that you can cover that in, let's say, two-thirds of the time. And now you got some headroom in front of you where you can turn the agenda over to them.

By building free time into the daily agenda, new engineering educators can spend more time eliciting, noticing, and responding to student thinking. This can help avoid the situation faced by Professor Aero, who said that he often ran short on time at the end of class when he had planned to ask clicker questions. As a result he often ended up rushing through the explanationsomething that he admitted was not ideal and would like to change in the future.

Continuing this discussion, Professor DV suggested that instructors aim to reduce their reliance on notes during class:

Don't use notes. [...] I think a lot of us early on walk into a classroom, we have really, really detailed notes. And we are holding onto our notes, $[. .$.$] looking at our notes, and$ $[\ldots]$ transcribing our notes and our thoughts. The sooner you can throw that away, you can free yourself up to receive [students'] thoughts, reflect, and think live on the fly.

Professor DV then clarified that he does bring notes to class, but they consist of an outline and one or two examples he wants to solve. However, he keeps the notes off to the side and rarely refers to them. Because he does not make his notes available to students and there is no textbook for the course, he does not have to worry about matching the notes he writes in class to any existing standard. Furthermore, Professor DV discussed how instead of using his notes to check that he got the right answer, he asks the students. As he stated, "I've got an audience of eighty people who are really good at algebra. If I make a mistake they're gonna find it for me." 
Professor DV did acknowledge that this is difficult the first time a new engineering educator teaches a class. However, it can serve as a goal that comes with experience:

I think when we start off we are [...] note-heavy lecturers. And, eventually, I think we can $[\ldots]$ move towards being just $[\ldots]$ outline-developers. Here's an agenda that I wanna get to and cover. And then put it aside. So you can't do that the first time you teach a class. You know, maybe the fifth or sixth time you can wean yourself from that. But I have found that to be really, really helpful.

\section{Conclusion}

Approaching formative assessment as responsive teaching is a powerful pedagogical technique that benefits both students and instructors. However, much of the research has focused on responsive teaching in K-12 mathematics, science, and engineering education. There is a need for further research that specifically investigates responsive teaching in undergraduate engineering education. Potential research questions include:

- What counts as disciplinary substance in engineering science courses?

- What activities or technologies allow instructors to elicit and notice student thinking in large lecture courses?

- What activities or technologies allow instructors to engage in responsive teaching practices outside of class?

- What professional development activities help instructors to develop their responsive teaching ability?

- How do engineering students benefit from responsive teaching practices?

We hope that new engineering educators will use the literature review, analysis of formative assessment in Aerodynamics and Dynamics \& Vibrations, and suggested practices in this paper as the basis for reflection about their own teaching practices. And, in doing so, participate in the continued conversation about responsive teaching in undergraduate engineering courses.

\section{References}

1) Ball, D. L. (1993). With an eye on the mathematical horizon: Dilemmas of teaching elementary school mathematics. The Elementary School Journal, 93(4), 373-397.

2) Bennett, R. E. (2011). Formative assessment: A critical review. Assessment in Education: Principles, Policy \& Practice, 18(1), 5-25.

3) Black, P., \& Wiliam, D. (1998). Assessment and classroom learning. Assessment in Education, 5(1), 7-74.

4) Black, P., \& Wiliam, D. (2009). Developing the theory of formative assessment. Educational Assessment, Evaluation and Accountability, 21(1), 5-31.

5) Chazan, D., \& Ball, D. (1999). Beyond being told not to tell. For the learning of mathematics, 19(2), 2-10. 
6) Coffey, J. E., Hammer, D., Levin, D. M., \& Grant, T. (2011). The missing disciplinary substance of formative assessment. Journal of Research in Science Teaching, 48(10), 1109-1136.

7) Dym, C. L., Agogino, A. M., Eris, O., Frey, D. D., \& Leifer, L. J. (2005). Engineering design thinking, teaching, and learning. Journal of Engineering Education, 94(1), 103-120.

8) Empson, S. B., \& Jacobs, V. R. (2008). Learning to listen to children's mathematics. In D. Tirosh \& T. Wood (Eds.), The International Handbook of Mathematics Teacher Education, Volume 2: Tools and Processes in Mathematics Teacher Education (257-281). The Netherlands: Sense Publishers.

9) Gray, G. L, Evans, D., Cornwell, P, Costanzo, F., \& Self, B. (2005) The Dynamics Concept Inventory Assessment Test: A Progress Report. Proceedings of the $112^{\text {th }}$ American Society for Engineering Education Annual Conference. Washington, DC: American Society for Engineering Education.

10) Hammer, D. (1997). Discovery teaching, discovery learning. Cognition and Instruction, 15(4), 485-529.

11) Hammer, D., Goldberg, F., \& Fargason, S. (2012). Responsive teaching and the beginnings of energy in a third grade classroom. Review of Science, Mathematics, and ICT Education, 6(1), 51-72.

12) Hora, M. T. (2015). Toward a descriptive science of teaching: How the TDOP illuminates the multidimensional nature of active learning in postsecondary classrooms. Science Education, 99(5), 783-818.

13) Jacob, B., Crespin, R., Libassi, CJ, \& Dynarski, S. M. (2016). Class size in Michigan: Investigating the risk of being in very large classes (University of Michigan Gerald R. Ford School of Public Policy Education Policy Initiative Policy Brief \#5). Retrieved from http://edpolicy.umich.edu/files/class-size-policy-brief-revised.pdf

14) Johnson, A. W., Wendell, K., \& Watkins, J. (2016). Dimensions of experienced responsive teaching in engineering. Proceedings of the 123rd American Society for Engineering Education Annual Conference and Exposition. Washington, DC: American Society for Engineering Education.

15) Lau, M. (2010). Understanding the Dynamics of Teacher Attention: Case Studies of how High School Physics and Physical Science Teachers Attend to Student Ideas (Doctoral dissertation). Retrieved from the Digital Repository at the University of Maryland.

16) Levin, D. M., Hammer, D., \& Coffey, J. E. (2009). Novice teachers' attention to student thinking. Journal of Teacher Education, 60(2), 142-154.

17) Mangiante, E. S., \& Moore, A. (2016). Attending, Analyzing, and Responding to Student Thinking for Engineering Design. Paper presented at the 2016 National Association for Research in Science Teaching Annual International Conference, Baltimore, MD, 14-17 April.

18) Maskiewicz, A. C., \& Winters, V. (2010, June). Interpreting elementary science teacher responsiveness through epistemological framing. In Proceedings of the 9th International Conference of the Learning Sciences-Volume $l$ (pp. 293-300). International Society of the Learning Sciences.

19) Mazur, E. (1997). Peer Instruction: A User's Manual. Upper Saddle River, NJ: Prentice-Hall.

20) McCormick, M., Wendell, K. B., \& O’Connell, B. P. (2014). Student Videos as a Tool for Elementary Teacher Development in Teaching Engineering: What Do Teachers Notice? Proceedings of the 121st American Society for Engineering Education Annual Conference. Washington, DC: American Society for Engineering Education.

21) Midkiff, K. C., Litzinger, T. A., \& Evans, D. L. (2001). Development of engineering thermodynamics concept inventory instruments. Proceedings of the $31^{\text {st }}$ Annual Frontiers in Education Conference. New York, NY: Institute of Electrical and Electronics Engineers (IEEE).

22) NGSS Lead States. (2013). Next Generation Science Standards: For States, By States. Washington, DC: The National Academies Press.

23) Pierson, J. L. (2008). The relationship between patterns of classroom discourse and mathematical learning (Doctoral dissertation). Retrieved from Texas ScholarWorks.

24) Popham, J. W. (2008). Transformative Assessment. Alexandria, VA: Association of Supervision and Curriculum Development.

25) Richards, J. (2013). Exploring what stabilizes teachers' attention and responsiveness to the substance of 
students' scientific thinking in the classroom (Doctoral dissertation). Retrieved from Digital Repository at the University of Maryland.

26) Richardson, J., Steif, P., Morgan, J., \& Dantzler, J. (2003). Development of a concept inventory for strength of materials. Proceedings of the $33^{\text {rd }}$ Annual Frontiers in Education Conference. New York, NY: Institute of Electrical and Electronics Engineers (IEEE).

27) Robertson, A. D., Scherr, R., \& Hammer, D., Eds. (2015). Responsive Teaching in Science and Mathematics. Routledge: New York, NY.

28) Sherin, M. G., \& Han, S. Y. (2004). Teacher learning in the context of a video club. Teaching and Teacher Education, 20(2), 163-183.

29) Sherin, M. G., \& Van Es, E. A. (2009). Effects of video club participation on teachers' professional vision. Journal of Teacher Education, 60(1), 20-37.

30) Vanderbilt University Center for Teaching. (n.d.). Classroom Assessment Techniques (CATs). Retrieved from https://cft.vanderbilt.edu/guides-sub-pages/cats/

31) Wendell, K. B., Watkins, J., \& Johnson, A. W. (2016). Noticing, assessing, and responding to students' engineering: Exploring a responsive teaching approach to engineering design. Proceedings of the 123rd American Society for Engineering Education Annual Conference and Exposition. Washington, DC: American Society for Engineering Education. 